\title{
EL INGENIERISMO CAMBIARIO. LA PESETA EN LOS AÑOS DEL CAMBIO MÚLTIPLE, 1948-1959*
}

\author{
JOSÉ MARÍA SERRANO SANZ \\ M. 'JESÚS ASENSIO CASTILLO \\ Universidad de Zaragoza
}

\section{RESUMEN}

El sistema de cambios múltiples para la peseta, vigente desde 1948 a 1959, ha planteado numerosos problemas a la historiografía española, pues implica desconocer el precio al que se hacían las operaciones exterior, enmascarado en la fronda de cambios especiales. En el presente trabajo se estima la serie de los diversos tipos de cambio promedio de toda la Balanza de pagos en el período, cubriendo el vacío que la posguerra representaba en la historia de la peseta. Además se calcula el tipo de cambio efectivo real, para concluir que las importantes devaluaciones de 1949 . 1951 y $1957-59$ fueron insuficientes para alcanzar el equilibrio entre los precios relativos de España y sus principales socios comerciales, por lo que la peseta se mantuvo sobrevalorada de forma continua a lo largo de los cuarenta y cincuenta.

Palabras clave: Peseta, Autarquía, Tipo de cambio, Tipos de cambio múltiples

\section{ABSTRACT}

The system of multiple exchange rates for the peseta, in force between 1948 and 1959, has posed many problems for Spanish historiography, in that it implies that the price at which foreign transactions were carried out is unknown, being hidden in the dense foliage of special exchange rates. In this paper we estimate the various average exchange rates series for all the Balance of Payments of these years, thus filling the vacuum that the post-Civil War period represents in the history of the peseta. We also calculate the real effective exchange rate, concluding that the

* Agradecemos los comentarios de Marcela Sabaté y de dos evaluadores anónimos. 
important devaluations of 1949-1951 and 1957-1959 were insufficient in order to achieve equilibrium between Spanish relative prices and those of its main trading partners, so that the peseta remained continuously over-valued throughout the 1940's and 1950's.

Keywords: Peseta, Autarky, Exchange rate, Multiple exchange rates.

\section{INTRODUCCIÓN}

En diciembre de 1948 se creó un sistema de cambios múltiples para la peseta, formalmente mantenido hasta abril de 1957, aunque, mediante primas y retornos, se prolongó hasta la unificación definitiva de los cambios en el Plan de Estabilización de 1959. Durante ese período los tipos aplicados en las operaciones comerciales eran específicos para productos concretos, variaban en las otras rúbricas de la balanza de pagos y todos ellos fueron, además, reiteradamente modificados. La fronda de cambios así conformada ha constituido un serio problema para el estudio de la economía española en el decisivo decenio de los cincuenta, pues se desconoce un dato tan fundamental como el tipo promedio al que se practicaron las operaciones con el exterior. Incluso en una perspectiva más amplia, la historia monetaria española desde la creación de la peseta o las relaciones económicas en el siglo veinte, se encuentran con el vacío de esa docena de años en las series del tipo de cambio.

El desconocimiento del cambio agregado vigente para la economía española ha producido un continuo desasosiego en los estudiosos del período y la adopción de múltiples paliativos que no resultan convincentes. $\mathrm{Ni}$ el tipo básico (10,95 ptas/dólar) era realista, pues apenas tenía virtualidad, ni el registrado en el mercado negro de Tánger relevante, porque no era percibido por la mayor parte de agentes económicos españoles ${ }^{1}$. La única solución adecuada consiste en adentrarse en la maraña de cambios y ponderar cada uno de los específicos con las operaciones a que hacía referencia, para obtener así el tipo al que efectivamente los agentes económicos españoles se

Un ejemplo repetido es el cálculo del coeficiente de apertura utilizando cualquiera de esos tipos de cambio cuando se parte de la balanza en dólares: con el tipo básico se obtiene una economía extremadamente cerrada al exterior y con el de Tánger extraordinariamente abierta (en torno al $3 \%$ y por encima del 20 , respectivamente). Ninguna de las dos tiene que ver con la realidad. Otro problema adicional es el enlace del sector exterior de los años cincuenta con el de los sesenta, pues aparece un salto inexistente en la realidad. Una explicación más completa de estos problemas puede verse en Serrano Sanz (1992). 
relacionaban con el exterior. En un trabajo anterior (Serrano Sanz, 1989) uno de los autores del presente artículo realizó una estimación de los tipos aplicados a las importaciones y exportaciones de mercancías. Aquí se reconstruyen de forma exhaustiva los correspondientes a toda la balanza de pagos, puesto que no sólo el comercio se vio afectado por la multiplicidad de cambios.

La serie del tipo de cambio elaborada permite apreciar la existencia de una fuerte devaluación de la peseta a finales de los cuarenta y comienzos de los cincuenta, que pasa inadvertida en los estudios del período, pero fue más intensa incluso que las de 1957 y 1959 consideradas conjuntamente. A pesar de ello la política de tipo de cambio no alcanzó a compensar el diferencial de precios acumulado en los dos decenios y la peseta se mantuvo permanentemente apreciada hasta el Plan de Estabilización. Con los nuevos datos se pueden comprender bien las dificultades del equilibrio externo a lo largo de los cincuenta.

El artículo comienza por describir el contexto y las prácticas de la política española de tipo de cambio, presenta después las series elaboradas y concluye con una estimación del tipo de cambio efectivo real, a partir de los tipos nominales vigentes para la economía española calculados en este trabajo.

\section{CONTROL DE CAMBIOS Y MULTIPLICIDAD DE TIPOS, RASGOS DEL PERÍODO}

Al término de la segunda guerra mundial la escasez de divisas era un obstáculo decisivo para restaurar el comercio y los flujos financieros internacionales en Europa, y el panorama sólo comenzó a despejarse con el inicio del Plan Marshall en 1948 y su masiva inyección de dólares. Hasta ese momento acuerdos bilaterales muy primitivos eran la norma, pero después las nuevas condiciones permitieron poner en marcha un multilateralismo cada vez más flexible, que culminó en 1950 con la Unión Europea de Pagos, al tiempo que se reordenaron los cambios con amplias y generalizadas devaluaciones. Un decenio más tarde la reconstrucción era un hecho y se pudo avanzar hasta la libre convertibilidad, disolviendo la Unión en diciembre de 1958 y dando protagonismo definitivamente el Fondo Monetario Internacional ${ }^{2}$.

2 El olvido del difícil contexto monetario internacional entre 1945 y 1960 es uno de los rasgos peculiares de casi toda la literatura española sobre aquel período; en ella parece contra- 
España había quedado al margen del programa de ayudas y tampoco tenía opción a incorporarse a los esquemas de cooperación institucional, por lo que la escasez de divisas no dejó de ser una realidad a lo largo de los cincuenta ${ }^{3}$. La mejoría de la coyuntura exterior a comienzos del nuevo decenio permitió aumentar las exportaciones y obtener algunos recursos adicionales, pero la «sed de importaciones» era tal que las nuevas divisas, como las obtenidas por los inicios del turismo o la ayuda americana, resultaban de continuo insuficientes ${ }^{4}$. El riesgo de quiebra del sector exterior llevó a practicar una complicada política defensiva, de la que formaba parte el manejo del tipo de cambio. El ingenierismo cambiario ${ }^{5}$ tomó vuelo en 1948, cuando el gobierno adquirió conciencia de lo que significaba la exclusión de las instituciones de cooperación en la posguerra, y tuvo dos componentes: un régimen estricto de control de cambios, continuación del practicado desde la guerra civil, y una multiplicidad de tipos de la peseta para las relaciones económicas con el exterior.

Las características fundamentales del control de cambios en la época fueron la inconvertibilidad interna y externa de la peseta y una regulación muy estricta de las transacciones exteriores ${ }^{6}$. La Ley de Delitos Monetarios de 1938, cuyo sólo nombre evoca bien la dureza de los tiempos, era la norma básica para las relaciones cambiarias, y el Instituto Español de Moneda Extranjera (IEME), creado en 1939, el organismo que monopolizaba el pa-

ponerse una idilica situación exterior, cimentada en un perfecto funcionamiento de las reglas de Bretton Woods, al reglamentismo español. La realidad era naturalmente más compleja, como muestra la consulta de cualquier trabajo sobre la situación monetaria internacional del período. A modo de ejemplo, pueden verse Ellsworth (1962), Tew (1965), Milward (1984,1992), Van der Wee (1986) o Eichengreen (1993).

3 El marco general de la economía española en la época, Donges (1976), Ros Hombravella y otros (1978), García Delgado (1987), Martínez Estévez (1987), Catalán (1993) y García Delgado y Jiménez (1996). Para los años previos, Catalán (1995). El comercio exterior, en Serrano Sanz (1997). Los datos básicos sobre aspectos monetarios y financieros, en Martín Aceña (1989).

${ }^{4}$ Sobre la necesidad de las importaciones habían insistido ya en la época autores como Manuel de Torres (1956) o Román Perpiñá (1960). También la revista ICE y quien era su director al final de los cincuenta, el profesor Fuentes Quintana. Véase ICE, julio 1959, o Fuentes Quintana (1959 y 1984).

5 Se utiliza aquí la expresión «ingenierismo» aludiendo a una construcción artificiosa y forzada, más que en el sentido de la mentalidad «ingenieril», propia de los ingenieros que dirigieron la política económica de los cuarenta, y a la que se han referido autores como M.J. González (1979) o C. Velasco (1984). Aunque, naturalmente, todo estaba relacionado, como simboliza la figura de Suanzes, ministro de Industria y Comercio, presidente del INI y director del IEME entre 1945 y 1950. Véase su gestión de aquellos años en Ballestero (1993), pp. 209 y ss. Asimismo Martín Aceña y Comín (1991), pp. 67 y ss.

${ }^{6}$ Eguidazu (1978), pp. 182 y ss. 
pel del Estado en este ámbito. La inconvertibilidad se traducía en la obligación de contar con autorización expresa del IEME para cualquier pago que los residentes quisieran hacer en divisas y para las transacciones que los no residentes hubieran de realizar en España. De otra parte estaba prohibida la tenencia de divisas, que habían de ser entregadas de inmediato para su conversión al IEME, organismo monopolista del depósito y comercio de todas las divisas. Estas eran las líneas generales del sistema de control de cambios vigente desde la guerra civil hasta la Estabilización de 1959, aunque su aplicación se adaptó a las circunstancias del momento. En la crisis de divisas 1946-1948 se endurecieron las normas y a partir de 1950 se fueron relajando de un modo progresivo y continuado, aunque sin desfigurar los principios antes mencionados.

La suave tendencia liberalizadora se inauguró en 1950 con la autorización de un mercado oficial de divisas en la Bolsa de Madrid ${ }^{7}$. En él se podían negociar ciertos porcentajes de los ingresos obtenidos por exportadores, así como divisas procedentes de transferencias recibidas por residentes, repatriaciones de capitales y turismo. Las divisas negociables eran: dólar norteamericano, francos francés, marroquí y suizo y escudo portugués, así como libras esterlinas en cheques o apuntes bancarios. Tanto la venta como

7 La creación se permitió mediante un Decreto del 21 de julio de 1950 y el mercado de divisas inició sus operaciones el 1 de agosto siguiente. En dicha disposición se aclaraba el origen de las divisas a negociar: a) Porcentajes de libre disposición para los exportadores, señalados en las licencias de exportación. b) Los cambios a realizar por extranjeros o españoles residentes en el exterior en viaje por España, así como los que efectúen los extranjeros residentes habituales. c) Las rentas en el exterior de capital y trabajo, comprendidas las relativas a propiedad intelectual e industrial, transferidas a favor de residentes en España. d) Las remesas desde el exte rior de auxilios familiares, socorros, pensiones, jubilaciones y otros conceptos análogos a favor de residentes en España. e) Las repatriaciones de capital que realizasen españoles residentes habituales en España. $f$ Las importaciones de capital que realizasen españoles residentes habituales en el extranjero. \& Las aportaciones de capital extranjero, debidamente aprobadas por los organismos competentes del Ministerio de Industria y Comercio, que se efectuasen a favor de empresas o actividades españolas, dentro de los límites señalados en las correspondientes autorizaciones y que habrían de ser expedidas para cada caso concreto por el IEME. Por su parte, las divisas que procedentes de las operaciones señaladas con anterioridad se ofreciesen para su venta en el mercado, podrían ser adquiridas y utilizadas con destino a las siguientes operaciones: a) El pago de las importaciones de mercancías, en la proporción que los correspondientes permisos indicasen que podían ser atendidos mediante divisas adquiridas en Bolsa. b) Los gastos de viaje por el extranjero. c) Las rentas en España de capital y trabajo a transferir a favor de residentes en el extranjero, comprendidas las relativas a propiedad intelectual $e$ in dustrial, salvo acuerdos concretos, debidamente aprobados al realizarse la aportación. d) Las remesas al exterior de auxilios familiares, socorros, pensiones, jubilaciones y otros conceptos análogos a favor de residentes en el extranjero. e) Las aportaciones de capital desde España para actividades económicas en el exterior, previas las oportunas autorizaciones del Ministerio de Industria y Comercio expedidas en cada caso concreto por el IEME. 
las adquisiciones - que debían tener un destino concreto- habían de ser sometidas al IEME y se tramitaban a través de bancos autorizados, de modo que las operaciones en divisas continuaban siendo estrechamente vigiladas y resulta exagerado hablar de transacciones libres. Sin embargo, el mercado de la Bolsa supuso un alivio en un mundo tan cerrado y funcionó aceptablemente, ofreciendo unos cambios intermedios entre los tipos del IEME y los del mercado negro de Tánger. Este era precisamente uno de los objetivos perseguidos, según confesaba la propia Exposición de motivos del Decreto: atraer divisas que de otro modo se evadían. El éxito del mercado aumentó desde finales de 1951 cuando se concedió un mayor margen de maniobra a los bancos que operaban en él, puesto que se permitió al IEME delegar funciones ${ }^{8}$. En 1954 se autorizó igualmente la negociación de divisas en las Bolsas de Barcelona y Bilbao.

Durante los cincuenta — «el decenio bisagra», en la conocida expresión de García Delgado " otras muchas disposiciones de carácter más concreto suavizaron aspectos particulares del régimen de control de cambios ${ }^{10}$, pero fue el Plan de Estabilización de 1959 el factor decisivo en el cierre de una etapa y el comienzo de otra. La declaración de convertibilidad exterior de la peseta en él contenida y la liberalización del mercado de divisas, junto a ciertos avances notables, aunque más tímidos, en las posibilidades de realizar operaciones en divisas, constituyeron un cambio radical, que singulariza esa fecha. Naturalmente, el significado del Plan de Estabilización no se agota en el ámbito de las relaciones monetarias exteriores - por más importante que éste sea-, sino que es unánime su consideración como un viraje radical en la política económica española del siglo ${ }^{11}$.

La no convertibilidad fue un rasgo generalizado en las divisas europeas durante los cuarenta y cincuenta y en modo alguno una peculiaridad de la

${ }^{8}$ Véase el texto refundido sobre el funcionamiento del mercado de divisas, publicado en el $\mathrm{BOE}$ de 30 y 31 de octubre de 1951. La novedad más importante fue que para la venta en Bolsa de las divisas no era necesaria ya la cesión de éstas al IEME, sino que se podía hacer a través del banco elegido por el interesado, de cuantos estaba autorizados a operar en el mercado. El banco debía ceder al Instituto la parte de divisas sometida al cambio oficial y negociaba con la restante.

${ }^{9}$ J. L. García Delgado (1987).

10 F. Eguidazu (1978) y M. J. Asensio (1995).

1 Estapé lo definió como «el conjunto de medidas más idóneas, mejor elaborada, mejor conjuntadas y con una trabazón más realista, con que cuenta la historia de la política económica española desde comienzos del siglo XX». En F. Estapé (1972), p. 310 . Entre la abundantísima literatura sobre el tema pueden señalarse Navarro Rubio (1976), M. J. González (1979), Viñas y otros (1979), Sardá (1987) y, a modo de síntesis, el balance de realizaciones y opiniones escrito con motivo del veinticinco aniversario del Plan, en E. Fuentes Quintana (1984). 
peseta ${ }^{12}$. Las restricciones en el comercio y tenencia de divisas existieron también en los demás países, aunque se fueron relajando más rápidamente que en España, gracias al alivio que supusieron el plan Marshall y la Unión Europea de Pagos como factores de relanzamiento de la cooperación y el crecimiento del comercio así amparado. Si en las limitaciones a la disposición de divisas por parte de los agentes económicos la diferencia fue de grado, el tipo de cambio múltiple alejó progresivamente a la peseta de las divisas del occidente europeo. En ese complejo sistema de fijación del tipo de cambio adquiere su verdadera dimensión el ingenierismo cambiario a que se hace alusión en el título de este artículo.

La opción de elegir un sistema de cambios en el cual la moneda tenga un valor diferente en función de la mercancía intercambiada, del carácter de importación o exportación del flujo o de la rúbrica de balanza de pagos a que pertenezca la operación con el exterior, resulta ser de una gran complejidad. El establecimiento de tipos de cambio múltiples había comenzado en algunos países durante la crisis de los treinta y, en su forma más elemental, consistía en devaluar el tipo aplicado a las exportaciones, con objeto de abrir mercados exteriores, mientras se encarecían relativamente las importaciones, manteniendo su tipo inalterado ${ }^{13}$. Tras la segunda guerra mundial Francia e Italia adoptaron un nuevo sistema que consistia en abrir un mercado libre para comerciar ciertas divisas, mientras la mayor parte de las importaciones y exportaciones se regían por un tipo oficial; como el de mercado se depreció de inmediato, apareció una dualidad, pronto eliminada en la reordenación monetaria de 1949.

En ese año, sin embargo, se mantenían tipos múltiples en dieciocho países, según el Fondo Monetario Internacional, con una estructura compleja, que sólo desde mediados de los cincuenta tendió a simplificarse ${ }^{14}$. Algunos países discriminaban las exportaciones en las que creían tener ventajas decisivas con tipos sobrevalorados, a modo de impuestos; otros favorecían importaciones estratégicas, como las de alimentos, maquinaria o materias primas, y penalizaban a los bienes de lujo discriminando sus tipos; los había que castigaban o alentaban movimientos de capital y quienes usa-

12 La revista ICE se referirá en su editorial de julio de 1959 a la declaración de convertibilidad de las monedas europeas de diciembre de 1958 como «una auténtica conmoción en la economía mundial» que «presionaba hacia una desvalorización cualitativa de la peseta, quizá la más grave de las desvalorizaciones que puede sufrir un signo monetario», p. 5.

${ }_{13}$ Véase Ellsworth (1962), pp. 371 y ss.

14 Van der Wee (1986), p. 522. Se trataba de países latinoamericanos, principalmente, y otros no europeos. 
ban el cambio para fomentar sus exportaciones o poner obstáculos a la importación. Como toda política compleja, la manipulación del tipo de cambio permitía a grupos de presión diversos utilizar el argumento del agravio comparativo y desembocaba en nuevas complejidades, arbitrariedades y pretendidas compensaciones, que la hacían aún más alambicada. Entre tanto los costes en términos de eficiencia iban aumentando para el conjunto de la economía, resultado de las interferencias en la asignación de recursos por los mercados y de las oportunidades de búsqueda de rentas abiertas en un mercado político que animaba a distraer recursos de la producción. De este ingenierismo cambiario participó España entre 1948 y 1959, en la forma que ahora se explicará.

El 3 de diciembre de 1948, por un Decreto se «autoriza al Ministerio de Industria y Comercio a establecer, con carácter transitorio y circunstancial, un sistema de cambios especiales aplicables a las exportaciones o importaciones de determinadas mercancías, así como a otras operaciones de carácter comercial o financiero». A pesar del pretendido carácter «transitorio y circunstancial», que indicaría se trataba de una medida coyuntural, adecuada a la crisis de divisas que se vivía, más que de una estrategia elaborada y a largo plazo de política económica, lo cierto es que el sistema pervivió un decenio ${ }^{15}$. Este puede ser considerado el inicio oficial de la política de cambios múltiples, aunque había venido precedido por algunas medidas de segundo orden en la misma dirección, también adoptadas en la crisis de divisas de la segunda mitad de los cuarenta. Se trataba de los cambios preferentes para ingresos por turismo, auxilio familiar y repatriación de capitales, así como de las cuentas especiales, que autorizaban a ciertos exportadores a utilizar directamente una parte de las divisas obtenidas en la importación de determinados bienes ${ }^{16}$.

Entre 1948 y 1959 se pueden distinguir tres etapas en la política de tipo de cambio: la primera abarca hasta 1950 y se caracterizó por un gran activismo e intensas devaluaciones; la segunda, en la que se cedió el protagonismo al mercado de divisas y se consiguió cierta estabilización de los cambios en los años centrales, se prolongó hasta 1957, y la tercera, entre este

15 La pretensión de que los tipos de cambio múltiples eran transitorios fue reiteradamente sostenida; así en 1951 el ministro Arburúa decía: «Este sistema cubre una etapa en el camino hacia la normalidad, ya que de momento es imposible ir a la fijación de un solo tipo de cambio, pues si se fijara el más elevado encarecería las importaciones, y si se estableciera uno más reducido, quedarían fuera del juego de las exportaciones todas aquellas mercancías que hoy salen a tipos más favorables». M. Arburúa (1956), p. 47. En el mismo libro, que recoge sus discursos de la etapa ministerial, hay otras manifestaciones en el mismo sentido.

16 Véanse F. Eguidazu (1978) y Viñas y otros (1979). 
año y el Plan de Estabilización, es la de una frustrada eliminación de los tipos múltiples, reaparecidos bajo la etiqueta de primas y retornos.

Publicado el Decreto que autorizaba los cambios especiales en diciembre de 1948 se establecieron hasta enero de 1949 nueve grupos de productos importables, con tipos que iban de 13,140 pesetas por dólar a 27,375, mientras se mantuvo el tipo básico de 10,95 pesetas por dólar para ciertas importaciones ${ }^{17}$. El dólar más barato se asignaba a la importación de alimentos y combustibles, cuyo comercio monopolizaba el propio Estado, mientras se encarecía algo para las materias primas, la maquinaria ocupaba un escalón intermedio y los bienes manufacturados se debían importar con el dólar más caro. En el caso de las exportaciones se establecieron 13 grupos que en los meses inmediatos se ampliaron a 15 , con cambios que iban de 12,59 a 21,90 pesetas por dólar, manteniéndose el tipo básico en 10,95. La lógica de estos grupos era menos nítida, pero, en líneas generales, la peseta más apreciada correspondía a los productos agrícolas y materias primas, mientras se intentaba facilitar la exportación de manufacturas con una peseta más barata ${ }^{18}$.

En octubre de 1949, siguiendo la oleada de devaluaciones de las monedas europeas, también la peseta se devaluó, aunque únicamente en el caso de los cambios especiales, puesto que los tipos básicos de importación y exportación permanecieron constantes. Los cambios especiales de importación se depreciaron muy uniformemente en torno a una media del $30 \%$, y quedaron fijados entre 15,760 y 39,401 pesetas por dólar. Los cambios especiales de exportación también se devaluaron, pero de un modo extremadamente irregular, tanto porque se reordenaron los grupos y se incorporaron nuevos productos, cuanto porque las modificaciones oscilaron entre un 16,7 y un $41,7 \%$; los tipos resultantes iban en una escala desde 15,30 a 28,47 pesetas por dólar. En los meses sucesivos los cambios de importación sufrieron escasas variaciones, pero no ocurrió lo mismo con los de exportación, en los que frecuentemente se alteraba algún tipo o se modificaba el grupo de referencia para ciertos productos.

La creación en julio de 1950 del mercado de divisas de Madrid supuso un giro notable en la política cambiaria, madurado a lo largo de ese año y el siguiente. En los primeros tiempos la discrecionalidad fue la norma, pues el porcentaje de divisas a vender o comprar en el mercado se fijaba indivi-

17 En realidad el tipo básico de las importaciones era 11,22 pesetas por dólar, pues a las 10,95 había que sumar 0,27 pesetas por dólar que el IEME cobraba en concepto de comisión por las ventas de divisas.

${ }^{18}$ Una reconstrucción completa de todos los cambios, en M. J. Asensio (1995). 
dualizadamente en cada licencia; en octubre se ordenaron las importaciones, pero en el caso de las exportaciones se tardó todavía un año en dejar de lado la discrecionalidad absoluta. En octubre de 1950 se clasificaron los productos de importación en siete grupos, a cada uno de los cuales se asignaba un tipo de cambio para las divisas adquiridas al IEME, el porcentaje de esas divisas que el citado organismo había de entregar al importador con licencia y el porcentaje a comprar en Bolsa ${ }^{19}$. Los cambios para las divisas vendidas por el IEME a los importadores iban desde 16,425 pesetas por dólar hasta 21,900 , aunque el cambio final dependía del porcentaje a comprar en Bolsa y del precio de la peseta en ese mercado. La reordenación de productos fue muy radical, pues quedaron los cambios favorables (peseta más apreciada y menor porcentaje de compra en el mercado libre) para alimentos y materias primas, mientras todo el resto de las importaciones —es decir, todas las manufacturas, incluyendo maquinaria - habia de hacerse con divisas compradas en el mercado de la Bolsa. Hasta 1957 numerosos productos cambiaron de grupo, generalmente para endurecer su situación, aunque las modificaciones más importantes se concentraron en 1953 y 1954.

Con respecto a las exportaciones la reordenación se produjo en octubre de 1951 con el establecimiento de un tipo de cambio básico de 21,90 pesetas por dólar y la definición de cinco grupos de mercancías, a cada uno de los cuales se autorizaba a vender en el mercado libre un porcentaje diferente de las divisas obtenidas por sus exportaciones ${ }^{20}$. Lógicamente en este caso los más beneficiados eran quienes podían vender libremente la proporción mas elevada, el $90 \%$. En un principio la clasificación era muy restrictiva, de manera que los grupos eran limitados y el tipo básico del IEME muy utilizado. Sin embargo, a los pocos dias comenzó un goteo de productos que fue restando importancia al cambio del IEME; en 1957, en el final de esta etapa, casi todas las ventas se hacían con el premio de un porcentaje colocado en la Bolsa. En general, las manufacturas tenían la situación más beneficiosa, mientras las exportaciones tradicionales, como frutas, aceite o frutos secos, se hallaban en posición intermedia.

Los cambios derivados de operaciones no comerciales, como turismo, inversiones, seguros o transferencias se introdujeron en enero de 1949, con unos tipos que iban de las 16,4 pesetas por dólar para fletes y seguros, a 25 para el turismo o las trasferencias. Unos meses más tarde, en octubre, coin-

${ }^{19}$ De los siete grupos, tres continuaban obteniendo el $100 \%$ de sus divisas en el IEME, dos tenian que adquirir el $40 \%$ en Bolsa, uno el 60 y otro el $100 \%$.

20 Los exportadores de mercancías clasificadas en el grupo 1 podían disponer del 10\% de las divisas para vender en el mercado, y los restantes de un $30,50,70$ y $90 \%$, respectivamente. 
cidiendo con la devaluación muy generalizada para la balanza comercial, se situó el cambio para fletes y seguros en 23,641 pesetas por dólar. A partir de la creación del mercado de la bolsa en julio de 1950 todas estas operaciones tuvieron en él su única referencia. Las operaciones habían de hacerse allí en régimen de mercado o bien directamente en el IEME o la banca autorizada, pero los tipos los fijaba semanalmente el IEME, tomando como promedio los de mercado en la semana anterior.

Con la creación del mercado de divisas se perseguía entre otros fines, como ya se indicó, reducir el mercado negro de pesetas, muy activo, cual corresponde a una situación de extremas restricciones. En Tánger estaba precisamente el más importante de ellos y el éxito de la Bolsa madrileña animó a las autoridades a intervenir incluso allí con el fin de estabilizar la peseta, en la primera mitad de los cincuenta ${ }^{21}$. Junto con el denominado programa dólar-peseta, que trataba de regularizar el suministro de algodón a los empresarios textiles ${ }^{22}$, se consiguió que entre 1953 y 1955 el cambio de Tánger y el de Madrid se aproximasen considerablemente. Sin embargo, a partir de la última fecha el crecimiento de las importaciones y los desequilibrios internos volvieron a resucitar los problemas de la peseta.

La respuesta fue el Decreto de 5 de abril de 1957, que devaluó la moneda y unificó los cambios en 42 pesetas por dólar; se abría así la última de las etapas consideradas. La medida se enmarca en el espíritu del denominado bienio pre-estabilizador, un período que tanto pudo ser preparación del 59 como solución pretendidamente definitiva, que hubo de ser rectificada dos años más tarde por haber quedado corta ${ }^{23}$. Al desaparecer la dualidad entre cambio oficial y de mercado, las normas que regían la Bolsa perdieron su sentido, de manera que a partir de abril de 1957 todas las divisas de origen comercial o financiero se podían vender en el mercado de la

${ }^{21}$ F. Eguidazu (1978), pp. 255 y ss.

22 El Programa dólar-peseta era un sistema de compensación llevado a cabo entre el Consorcio de Industriales Textiles Algodoneros (CITA), la firma comercial World Commerce Corporation (WCC) y el IEME para evitar que los empresarios del textil tuviesen que recurrir al mercado de Tánger regularmente, a fin de conseguir divisas para importar algodón. El que fuera director en los años cincuenta del CITA, Manuel Ortínez, ha explicado en un delicioso libro de memorias el ambiente de aquellos años y los viajes a Tánger, ejerciendo —en su propia expresión- de «contrabandista honrado»; en los años sesenta fue nombrado director del IEME, por lo que pasó a ser «carabinero en Madrid». Cuenta en ellas que al proponerle el nombramiento advirtió de su pasada condición y la respuesta fue «que aixó mateix era el que buscaven: algú que conegués el negoci y que fos capaç de desmuntar-lo», M. Ortínez (1993), p. 57.

${ }^{23}$ Sobre el bienio, véanse Ros Hombravella y otros (1978), M. J. González (1979) y Viñas y otros (1979). En cuanto al problema presupuestario, una de las claves del bienio, porque la necesidad de acabar con el déficit público impulsó también las reformas, véase Comín (1996). 
Bolsa, sin porcentajes intervenidos por el IEME. Las únicas cuyo cambio monopolizaba el Instituto a partir de ese año eran las provenientes de inversiones de capital extranjero. Para las compras con cualquier finalidad continuaba siendo requisito imprescindible la autorización individualizada y expresa del IEME. El nuevo tipo de cambio estaba por debajo del que regía en los mercados internacionales libres $(50,85$ pesetas por dólar en Tánger) y pronto se advirtió que resultaba insuficiente para contener los problemas de balanza de pagos.

Se inició entonces una vuelta hacia los cambios múltiples, nunca reconocida como tal, pues se enmascararon en un complejo sistema de primas y retornos. Fue, de otro lado, un retroceso, pues apareció de nuevo la arbitrariedad, con multitud de concesiones ad hoc, en las que se especificaban tipos concretos para operaciones particulares. Como acostumbraba a suceder en circunstancias tales, las primas comenzaron siendo concedidas a un número reducido de exportaciones, pero a partir de 1958 el goteo fue creciente, y esto obligaba a incrementar los recargos o retornos para financiarlas, de manera que la maraña de cambios volvió a ser una realidad. A ello contribuyó el secretismo de las autoridades, temerosas de la reacción de las organizaciones internacionales, que no veían con buenos ojos las subvenciones a la exportación y la discrecionalidad, y hasta de la propia opinión pública, por más limitado que fuera el papel jugado por ésta ${ }^{24}$. Las primas se concedían a ciertos productos de exportación, como estímulo por encima del cambio oficial, y se financiaban con recargos sobre algunas importaciones y también sobre determinadas exportaciones, denominados retornos. A principios de 1959 existían de nuevo múltiples tipos de cambio diferentes para la peseta, que iban de 31 a 45 pesetas por dólar en el caso de las exportaciones y de 42 a 84 para las importaciones, con alguna excepción ${ }^{25}$. Las primas eran para ciertos artículos tradicionales de exportación que estuviesen elaborados, como las conservas o los zumos, y los retornos se cargaban sobre minerales de exportación o artículos considerados de lujo en las importaciones.

${ }^{24}$ En octubre de 1958 el subscretario de Comercio se mostraba partidario de no dar publicidad a los retornos que acababan de aprobarse, aduciendo las siguientes razones: «1) Por la dificultad que nos crearía admitir públicamente que necesitamos suplir el agotamiento del Fondo de Retorno, para continuar dando primas a la exportación, primas que la OECE reprueba y en la que pretendemos ingresar; 2) Porque si bien indirectamente afecta a todos los españoles por la repercusión en los precios, directamente sólo afecta al grupo que ya está enterado. Muchos ciudadanos que ignoran la existencia del Fondo de Retorno la conocerían en un momento en que se les anuncia como un factor más de alza de costes de vida». Acta del Fondo de Retorno de Cargas Interiores de 18 de octubre de 1958.

${ }^{25}$ Véase J. M. Asensio (1995). 
El fracaso de este sistema fue doble: se había vuelto al camino de la discrecionalidad y las interferencias en el mercado y no sirvió para solucionar el problema del cambio, ni para equilibrar la balanza. La nueva situación crítica se afrontó en 1959 con mayor energía y de una forma que resultó definitiva, con la devaluación a 60 pesetas por dólar, la unificación del tipo de cambio y la convertibilidad de la peseta, tres elementos esenciales del Plan de Estabilización expresivos de una racionalidad económica al fin impuesta ${ }^{26}$. El ingenierismo cambiario había quedado atrás.

\section{EL TIPO DE CAMBIO PROMEDIO EN LOS AÑOS DEL CAMBIO MÚLTIPLE}

Tal como se indicó, la existencia de una multiplicidad de cambios para las operaciones de balanza de pagos entre 1948 y 1959 plantea un serio problema a los investigadores, pues se desconoce el tipo agregado de la peseta al cual la economía española se relacionó con el exterior. Para reconstruirlo hay que proceder en dos etapas. Primero, es preciso desentrañar, del modo más exhaustivo posible, la maraña de cambios especiales que afectaban a las distintas operaciones exteriores, aclarando el período concreto de su vigencia. A partir de 1950 ese cambio se debe combinar en muchos casos con el de la Bolsa, en la proporción del porcentaje de divisas negociable, que era también variado. Una vez elaborada dicha información se puede pasar a la segunda etapa, la construcción de los tipos promedio; para ello es necesario conocer el peso relativo de cada una de las operaciones afectadas por los diversos cambios especiales, en los respectivos períodos de tiempo, a fin de establecer las correspondientes ponderaciones. De ese modo se obtienen series del tipo de cambio de importaciones, exportaciones e ingresos y pagos por servicios, transferencias y capitales. Ponderándolas de nuevo, adecuadamente, se puede conocer el tipo de cada una de las balanzas parciales y también de la balanza de pagos globalmente considerada. Estos son los cálculos que hemos realizado y los resultados se presentan a continuación (Cuadros 1,2 y 3 ), aunque previamente convendrá aclarar algunos extremos ${ }^{27}$.

El ámbito más complejo es el comercio, puesto que la multiplicidad de tipos era en este caso verdaderamente espectacular y las modificaciones de

26 E. Fuentes Quintana (1995) y J. Velarde (1995).

${ }^{27}$ La información que sirve de base para los distintos pasos es tan prolija que resulta imposible aportarla en el reducido espacio de un artículo en una revista científica. Sin embargo, se encuentra a disposición de los investigadores interesados. 


\section{CUADRO 1}

Tipos de cambio de la balanza comercial

\begin{tabular}{lccc}
\hline & $\begin{array}{c}\text { Cambios } \\
\text { importación }\end{array}$ & $\begin{array}{c}\text { Cambios } \\
\text { exportación }\end{array}$ & $\begin{array}{c}\text { Cambios promedio } \\
\text { de la balanza } \\
\text { comercial }\end{array}$ \\
\hline 1949 & 16,438 & 13,067 & 14,97 \\
1950 & 21,805 & 17,426 & 19,57 \\
1951 & 31,373 & 25,084 & 27,94 \\
1952 & 31,891 & 27,797 & 30,16 \\
1953 & 31,438 & 28,378 & 30,07 \\
1954 & 33,454 & 28,987 & 31,53 \\
1955 & 35,373 & 29,441 & 32,88 \\
1956 & 34,419 & 29,757 & 32,71 \\
1957 & 40,034 & 39,367 & 39,80 \\
1958 & 43,418 & 43,178 & 43,33 \\
1959 (I) & 46,959 & 44,733 & 46,17 \\
1959 (II) & - & - & 60,00 \\
\hline
\end{tabular}

los mismos frecuentes. En particular, por el lado de las exportaciones, y durante los primeros y últimos años, de 1949 a 1951 y de 1957 a 1959, es donde se concentra el grueso de los problemas. Los tipos aplicables al comercio de exportación variaban a menudo, probablemente a consecuencia de las presiones que los exportadores debían ejercer para mejorar los cambios tan apreciados que, en general, tenía la peseta en su caso (Cuadro 1). Durante los primeros años las modificaciones fueron muy frecuentes -un coste lógico de un sistema tan complejo- y después el mercado de divisas proporcionó cierto automatismo que redujo las intervenciones discrecionales ${ }^{28}$. A partir de 1957 el problema para el investigador radica en el secretismo con que se condujo el sistema de primas y retornos, ya señalado con anterioridad ${ }^{29}$. A cambio de estas dificultades en la reconstrucción de los tipos de cada producto, la información sobre los flujos comerciales es la más

${ }^{28}$ Un obstáculo adicional de los primeros años es el desfase entre la apertura del mercado de divisas de Madrid y la ordenación de los porcentajes negociables en él para cada producto; el problema no es muy grave, sin embargo, porque la introducción de divisas procedentes de flujos comerciales en el mercado bursátil fue muy lenta: de acuerdo con el Archivo del IEME (AHBE, Departamento Extranjero, Secretaría, Caja 164, Antiguo 48.003) sólo el 0,9\% de las importaciones y el 2,5 de las exportaciones en 1950 se canalizaron a través de la Bolsa.

${ }^{29}$ La estimación se ha hecho a partir de las Actas de la Comisión del Fondo de Retorno, las Actas del Consejo de Ministros, la revista ICE semanal, las publicaciones del Banco Exterior de España y una del Fondo Monetario Internacional de febrero de 1959. El FMI hizo un cálculo de 


\section{CUADRO 2}

Tipo de cambio de las balanzas de servicios, transferencias y capitales a largo plazo

\begin{tabular}{ccccccc}
\hline & \multicolumn{2}{c}{ Servicios } & \multicolumn{2}{c}{ Transferencias } & \multicolumn{2}{c}{ Capitales a largo plazo } \\
\cline { 2 - 7 } & Ingresos & Pagos & Ingresos & Pagos & Ingresos & Pagos \\
\hline 1949 & 21,450 & 17,796 & 24,768 & 25,000 & 16,400 & 10,950 \\
1950 & 30,872 & 30,271 & 30,750 & 31,139 & 26,137 & 10,950 \\
1951 & 39,797 & 38,824 & 39,780 & 39,798 & 39,798 & 10,950 \\
1952 & 39,650 & 39,064 & 39,623 & 39,650 & 39,650 & 10,950 \\
1953 & 40,367 & 38,442 & 41,777 & 39,558 & 40,700 & 10,950 \\
1954 & 39,074 & 37,175 & 37,256 & 38,950 & 41,666 & 20,095 \\
1955 & 38,295 & 37,916 & 34,608 & 38,950 & 37,789 & 15,527 \\
1956 & 38,771 & 36,702 & 38,105 & 38,950 & 39,755 & 16,633 \\
1957 & 41,864 & 41,110 & 41,511 & 41,110 & 41,517 & 34,732 \\
1958 & 43,432 & 42,000 & 41,813 & 42,000 & 43,984 & 42,000 \\
\hline
\end{tabular}

\section{CUADRO 3}

Tipos de cambio estimados para la balanza básica, tipo oficial y del mercado de Tánger

\begin{tabular}{|c|c|c|c|c|c|}
\hline & \multicolumn{3}{|c|}{ Balanza básica } & \multirow{2}{*}{$\begin{array}{c}\text { Tipo de cambio } \\
\text { oficial básico }\end{array}$} & \multirow{2}{*}{$\begin{array}{c}\text { Tipo de cambio } \\
\text { mercado } \\
\text { de Tánger }\end{array}$} \\
\hline & Ingresos & Pagos & Promedio & & \\
\hline 1949 & 14,373 & 16,475 & 15,38 & 10,95 & 40,27 \\
\hline 1950 & 18,788 & 22,688 & 20,60 & 10,95 & 52,52 \\
\hline 1951 & 27,127 & 31,571 & 29,11 & 10,95 & 51,27 \\
\hline 1952 & 29,861 & 32,465 & 31,21 & 10,95 & 48,54 \\
\hline 1953 & 32,234 & 32,108 & 32,16 & 10,95 & 43,30 \\
\hline 1954 & 32,492 & 33,561 & 32,99 & 10,95 & 42,98 \\
\hline 1955 & 33,029 & 35,461 & 34,11 & 10,95 & 43,16 \\
\hline 1956 & 34,156 & 34,533 & 34,32 & 10,95 & 45,19 \\
\hline 1957 & 40,409 & 40,112 & 40,24 & $10,95 / 42$ & 53,95 \\
\hline 1958 & 43,189 & 43,210 & 43,19 & 42 & 54,99 \\
\hline 1959 (I) & - & - & - & 42 & 59,39 \\
\hline 1959 (II) & - & - & - & 60 & - \\
\hline
\end{tabular}

NotA: Tipo de cambio de Tánger: Ros Hombravella y otros (1978).

los tipos ponderados a finales de 1958 y consideraba que el $43 \%$ de la importación se hacía a 42 ptas y el $42 \%$ a 52,77 ; del resto no había información; en las exportaciones el cambio base ser vía para un $26 \%$, mientras un $16 \%$ y un 12 se hacian, respectivamente, a 48 y 50 ptas. También la OCDE hizo sus cálculos para el comercio de 1957. Véase Viñas y otros (1979), pp. 901 y 983 
abundante, gracias a las Estadísticas de Comercio Exterior. Con ellas se han hecho unas ponderaciones de la balanza comercial, para las cuales se ha debido establecer una correspondencia entre sus epígrafes y los productos con tipos especiales, que venían definidos de un modo muy concreto.

La información sobre flujos financieros y de servicios es mucho más incompleta y poco sistemática. Por esa razón se ha preferido utilizar para las ponderaciones la Balanza de pagos reconstruida por Chamorro y otros (1975), que proporciona un cuadro completo de tales operaciones, en lugar de los datos fragmentarios de que se dispone en los archivos ${ }^{30}$. En consecuencia, los cambios de los distintos componentes de la balanza básica y de ésta se han agregado a partir de tales ponderaciones. Al contrario de lo que sucedía con el comercio, la sistematización de los tipos es aquí más sencilla, pues se publicaban en el Boletín Oficinal del Estado las cotizaciones que regían con carácter general.

En ciertas ocasiones, no obstante, se establecían tipos específicos para operaciones concretas, por lo que también se han considerado; esto ocurrió con la ayuda del Protocolo Franco-Perón, los préstamos del Export-Import Bank, las transacciones realizadas a través de la firma World Commerce y la ayuda americana, privada y pública. La amortización del préstamo argentino se realizó al tipo de cambio básico, y otro tanto ocurrió con los pagos gubernamentales de la balanza de capital a largo plazo y, en general, los gastos del Estado, de acuerdo con los archivos del IEME ${ }^{31}$. Los préstamos concedidos a comienzos de los cincuenta por el Import-Export Bank se amortizaron al cambio general que regía para las operaciones financieras ${ }^{32}$. La ayuda americana comenzó a ser significativa a partir de los Pactos de 1953 y tuvo dos componentes principales: el programa de defensa, ampliado desde 1955 tras la Enmienda McCarran, y la Ley Pública 480 de Excedentes agricolas $^{33}$. El programa de defensa financiaba importaciones que la parte española pagaba en pesetas, mientras el gobierno americano compensaba a los

31) Esto obliga a realizar ponderaciones anuales, mientras en la balanza comercial, se podían actualizar mensualmente, gracias a las Estadísticas oficiales del comercio exterior, de modo que los tipos obtenidos son más precisos en este segundo caso.

31 «Determinación del cambio medio resultante para las salidas de divisas calculado sobre las cesiones efectuadas en el año 1953 y en base a los cambios vigentes en 30 de junio de 1954». AHBE, Departamento Extranjero. IEME. Secretaría. Caja 164, Antiguo 48.003.

32 Decreto de 16 de marzo de 1951, modificado parcialmente por el Decreto de 13 de diciembre de 1951 y la Orden de 4 de febrero de 1952.

${ }^{33}$ Sobre la Ayuda americana, véanse Ros Hombravella y otros (1978), pp. 249 y ss.; Eguidazu (1978), pp. 265-266; Viñas y otros (1979), pp. 741 y ss.; Viñas (1981), pp. 251 y ss., y Tamames (1975), pp. 460 y ss. 
vendedores en dólares; las pesetas se depositaban en el IEME y éste las traspasaba a unas «cuentas de contrapartida» en el Banco de España, para su distribución entre el gobierno americano, que realizaba algunos pagos en España (construcción y sostenimiento de las bases), y el gobierno español, que recibía así una parte de fondos. La Ley Pública 480 financiaba importaciones de productos agrícolas norteamericanos y a través de ella se ofrecían otros como donativo. Los tipos de cambio se pactaron entre las dos partes y eran parecidos a los que regían para las restantes operaciones financieras ${ }^{34}$.

Las series obtenidas ilustran la existencia de una política activa de cambios que, a través de la fronda de tipos múltiples, fue devaluando continuadamente la cotización de la peseta en relación con el dólar. Una política con un doble sentido: microeconómico, pues discriminaba unas transacciones y otras, pero también macroeconómico, pues modificaba el tipo agregado. Este último era difícilmente perceptible hasta no disponer de las series que aquí se presentan, aunque ahora resulta inequívoco. La devaluación de la peseta entre 1948 y 1959 fue una constante, pero no siguió ritmos uniformes en los diferentes tipos de cambio, ni se distribuyó en el tiempo de forma regular. Por ello convendrá analizar una por una las series obtenidas, antes de proceder a emitir juicios sobre la política cambiaria de los cincuenta.

El rasgo más llamativo al examinar los cambios de la balanza comercial (Cuadro 1 y Gráfico 1) es la intensidad de las devaluaciones y su concentración en dos momentos 1948-1951 y 1957-1959, precisamente al comienzo y final del período. Contra la imagen tópica, además, las grandes devaluaciones no son las de 1957-1959, sino las que tienen lugar a finales de los cuarenta y en el umbral del nuevo decenio ${ }^{35}$. En promedio la peseta utilizada para el comercio exterior se había depreciado en 1951 un $225 \%$ respecto a 1948 , mientras lo hizo un $183 \%$ en 1959 , tomando como punto de partida 1956. Estos resultados son, en nuestra opinión, importantes, porque ilustran la intensidad del esfuerzo estabilizador en la vertiente exterior de la economía española de finales de los cuarenta y comienzos de los cincuenta, escasamente mencionado en los trabajos sobre la época ${ }^{36}$. El saneamiento del sector exterior entonces promovido, aunque insuficiente, debió tener

${ }^{34}$ En el Informe sobre la Economía española del Banco de España en 1959 aparecen los valores de las mercancías importadas a través de la ayuda y la ley 480 , en dólares y pesetas, de donde se puede obtener el cambio efectivo de las mismas.

Devaluaciones de la peseta que son paralelas a la caída de las reservas de oro del IEME, reducidas en 1950 a la mitad del valor que tenían en 1948. Martín Aceña (1988), p. 82.

36 Una excepción en el panorama, en J. Velarde (1991), aunque se refiere principalmente a la vertiente interna de la estabilización de 1948. 


\section{GRÁFICO 1}

Tipo de cambio de la peseta (promedios de la balanza comercial y básica y mercado de Tánger

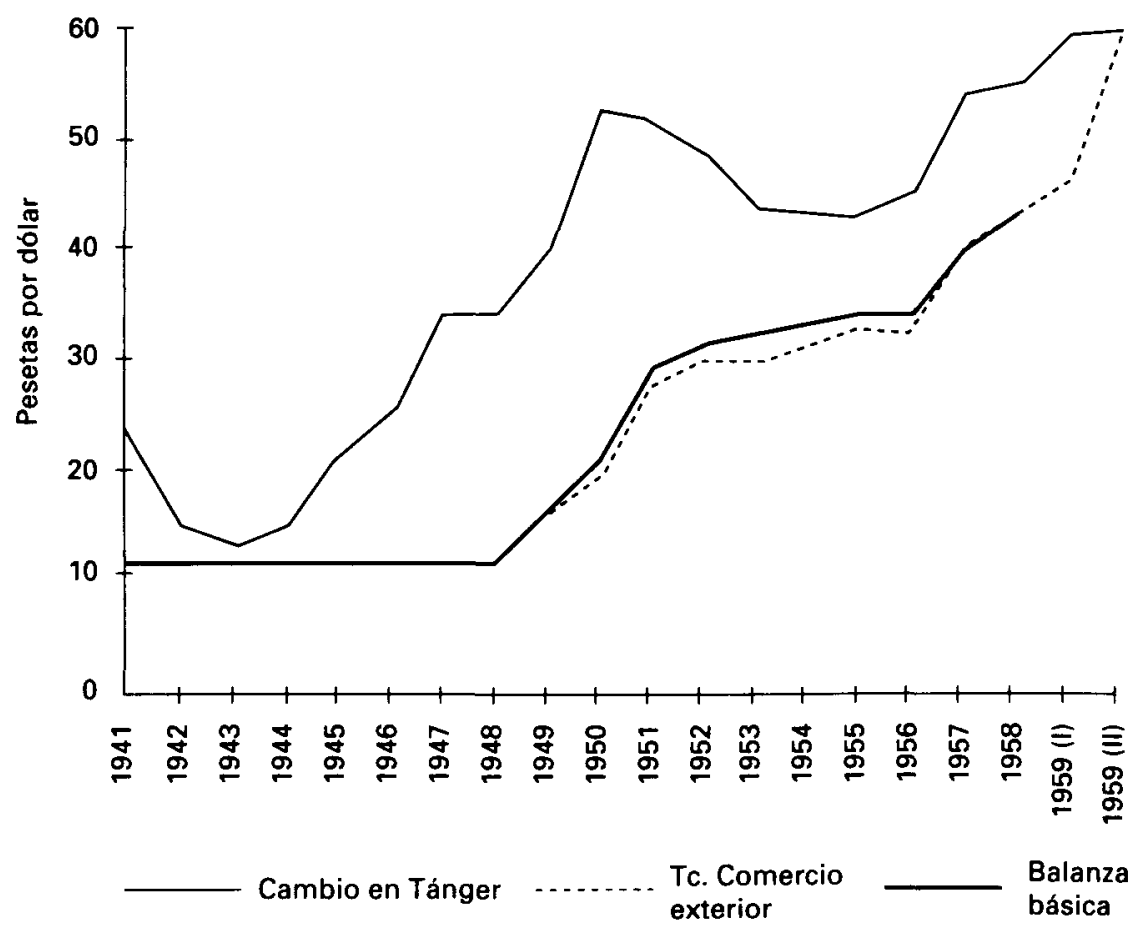

consecuencias decisivas en la mayor holgura de la balanza de pagos durante la primera mitad de los cincuenta. En esta perspectiva, el nuevo gobierno de 1951 tal vez no fue el factor decisivo en la tímida apertura, sino que ésta habría sido posible gracias a las devaluaciones previas. Definitivamente los precios relativos resultan más poderosos como explicación del cambio económico que la ideología o el voluntarismo de los ministros.

Entre uno y otro período devaluador el tipo de la peseta se mantuvo relativamente estable en los primeros cincuenta, aunque la tendencia a la depreciación era siempre inequivoca y más a mitades del decenio. Los promedios señalados esconden diferencias notables entre los cambios para importaciones y exportaciones en uno y otro momento; la devaluación fue más intensa para el comercio de importación en los primeros años $(286 \%$ 


\section{GRÁFICO 2}

Los tipos de cambio de importaciones y exportaciones

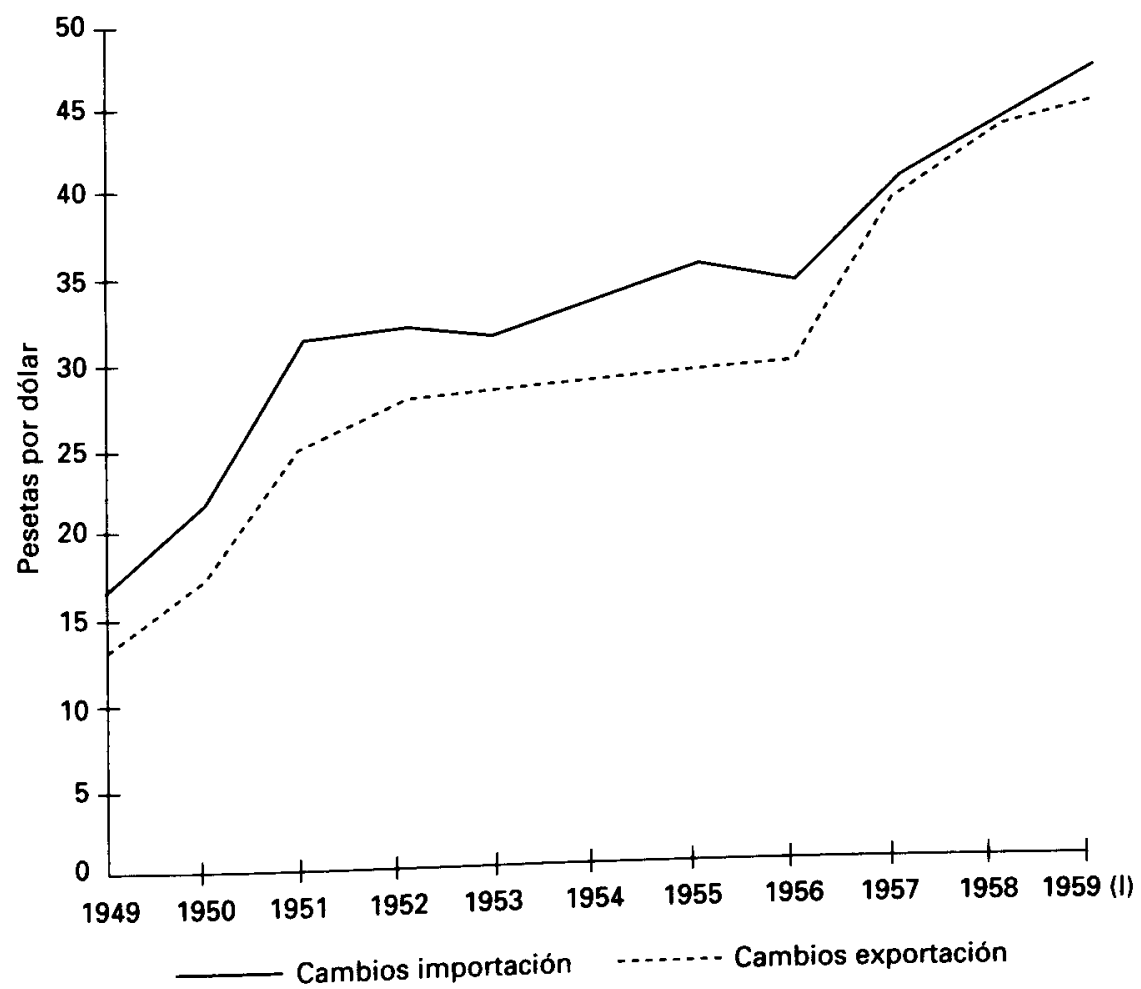

frente a 229), mientras en la unificación de cambios en 1959 se produjo el efecto contrario ( $174 \%$ y 200 , respectivamente).

Consecuencia directa de lo que se acaba de señalar es un segundo rasgo destacable en las series del cambio para la balanza comercial: la peseta se encontraba claramente más apreciada para las exportaciones que para las importaciones (Gráfico 2). Ello significa que los importadores pagaban caros los dólares que adquirían y los exportadores recibían escasas pesetas por sus dólares. Quienes obtenían los beneficios más claros de ese tratamiento diferencial eran los intermediarios en las transacciones, con el IEME en primer término; el Instituto podía así financiar operaciones políticas como las compras para abastecimiento a precios bajos o la amortización de deuda ex- 
terna con tipos de la peseta muy apreciados y reducido coste para el estado. Las diferencias se redujeron drásticamente a partir del intento de unificación de 1957, aunque en el primer semestre de 1959 se estaban de nuevo ampliando en el marco del sistema de primas y retornos. De otro lado, las diferencias obligan a no perder de vista la perspectiva microeconómica, pues no todas las exportaciones eran tratadas por igual, ni tampoco las importaciones, e incluso había algunas de éstas para las que se utilizaron tipos de la peseta más apreciados que los promedios de exportación.

Los perfiles de las series del tipo de cambio de la peseta que efectivamente rigieron para las balanzas de servicios, transferencias y capitales, diferían de manera considerable respecto al que presentaban los tipos de la balanza comercial. Los tipos de servicios y transferencias eran muy parecidos entre sí, y se caracterizaron por una considerable estabilidad a lo largo de los cincuenta, tras una devaluación inicial mucho más intensa que en el caso de los correspondientes al comercio; tras situarse en el entorno de las 40 pesetas por dólar ya en 1951, permanecieron hasta la devaluación de 1959. Cabe destacar también las escasas diferencias entre los tipos de compra y venta de divisas, algo que se explica por un menor intervencionismo discriminador del IEME, pues los cambios se negociaban en el mercado de la Bolsa en elevadísima proporción. En cualquier caso, la rápida e intensa devaluación muestra el interés de las autoridades por atraer divisas, vía turismo, remesas y también —aunque con matices, como ahora se explicarácapitales.

Los cambios de la balanza de capitales presentaban muchas peculiaridades, comenzando por una notable diferencia entre los que se aplicaban a los ingresos y los que servían para los pagos. Los primeros tenían un perfil muy parecido a las series de servicios y transferencias, mientras los tipos aplicados a los pagos mantuvieron la peseta continuadamente muy apreciada y anclada hasta mediados de los cincuenta en el tipo básico. La razón de tal peculiaridad es el peso del capital público en este epígrafe de la balanza de pagos de la época; en esas condiciones las autoridades abarataban considerablemente el coste en pesetas -es decir, para ellas- de la devolución de préstamos, como el que hizo Argentina. El coste así evitado se cargaba al IEME, pues era quien debía ceder los dólares a un precio artificial; lógicamente, el IEME repercutía ese coste sobre los agentes que intervenían en las transacciones de divisas, principalmente importadores y exportadores, los más sometidos a sus regulaciones, como ya se ha indicado. El interés por captar capital privado a largo plazo y también divisas, junto con la pérdida de protagonismo de las operaciones de capital público, llevó a finales de los 
cincuenta a un acercamiento de tipos hacia los vigentes para el resto de la balanza de pagos.

Una vez analizado el comportamiento de cada una de las series de tipo de cambio por separado, puede resultar útil adoptar una perspectiva de conjunto y comparar el tipo que efectivamente rigió para la economía española, con otro que tuvo su trascendencia en aquel tiempo, el del mercado libre de Tánger, pues es sabido que una parte no despreciable de las transacciones de pesetas contra divisas se realizaba alli ${ }^{37}$. Como se trataba de un mercado en el cual la cotización de la peseta era idéntica para todo tipo de intercambios, debe hacerse la comparación con el tipo teórico más general entre los obtenidos, el de la balanza básica; aunque la importancia de la balanza comercial en la época hace interesante confrontarlo asimismo con el de ésta (Gráfico 1).

El mercado de Tánger se había consolidado tras la guerra civil como un centro estratégico en la negociación de moneda española por extranjeras, y en él cotizaba la peseta a un valor inferior al oficial. De 1941 a 1943 fue mejorando su posición, pero el cambio de perspectivas en la guerra mundial y la situación cada vez más apurada de la economía española invirtieron la tendencia entre 1943 y 1950 , cuando pasó de 13,25 pesetas por dólar a 52,52. A finales de 1948 la peseta cotizaba a 37,50 por dólar en Tánger ${ }^{38}$, mientras el cambio oficial básico del IEME continuaba siendo 10,95 pesetas por dólar. Como ya se indicó había algunas excepciones, pues se habían establecido cambios especiales para el turismo, las transferencias y ciertas operaciones individualizadas de comercio, pero todo ello era poco relevante cuantitativamente. Desde el establecimiento de los cambios múltiples y el mercado de divisas de Madrid se fue produciendo un paulatino acercamiento, forzado a mitad de los cincuenta con intervenciones estabilizadoras del propio IEME, que incluso consiguió una cierta revalorización de la peseta en Tánger entre 1950 y 1954, aunque después volvió a depreciarse hasta las 59,39 de comienzos de 1959. La devaluación de julio, en el marco de la estabilización, situó la cotización oficial en 60 pesetas por dólar, de manera que se aceptó, en realidad, el tipo de cambio de Tánger, poniendo fin a una dualidad cambiaria que se había prolongado a lo largo de los dos decenios precedentes.

${ }^{37}$ En realidad, el tipo verdaderamente aplicable a la economía española habría de tener en cuenta ese mercado y debería ser una media ponderada entre el que aquí se presenta y el de Tánger; al no disponer del volumen de intercambios canalizado por la vía africana es imposible considerarlo. Parece, no obstante, claro, a tenor de las informaciones conocidas, que era una parte reducida del total, de manera que el tipo final estaría muy cerca del calculado por nosotros.

${ }^{38}$ Donges (1976), p. 49. 


\section{PRECIOS Y CAMBIOS: \\ LA CUESTIÓN DE LA COMPETITIVIDAD}

Un sistema de cambios con valores de la moneda diferentes en función de la mercancía que se comercia, el carácter de importación o exportación del flujo, o la rúbrica de balanza de pagos a que pertenezca la operación con el exterior, produce efectos muy complejos en la economía. Unos pertenecen al ámbito microeconómico, pues la discriminación establecida altera la asig. nación de recursos, en beneficio de ciertas actividades y perjuicio de otras. Otros, como el efecto sobre la competitividad global de la economía, son de tipo macroeconómico y pueden analizarse considerando los cambios múltiples de forma agregada.

Durante el período examinado, en el que España apenas tenía compromisos internacionales, el intervencionismo gubernamental fue intenso y el margen para la fijación del tipo de cambio elevado. Las consecuencias de ese intervencionismo en términos de competitividad, es decir, en términos de una posible sobrevaloración o infravaloración de la peseta, a la vista de la evolución de los precios relativos, sólo pueden analizarse si se dispone de los tipos agregados o promedio del período. Una vez calculados estos últimos, pasamos a comparar, en este apartado, su evolución con los precios relativos.

Tomaremos como indicador de competitividad un índice del tipo de cambio efectivo real, definido como

$$
T C E R=T C E N \cdot I P R
$$

siendo el tipo de cambio efectivo nominal

$$
\operatorname{TCEN}=\left[\Pi_{i}\left(E_{0} / E_{t}\right)^{x i}\right] \cdot 100
$$

y el índice de precios relativos

$$
I P R=\left[\left(C P_{t} / P_{0} / \Pi_{i}\left(P_{t}^{*} / P_{0}^{*}\right)^{x i}\right] \cdot 100\right.
$$

donde $E_{0}$ y $E_{t}$ son el tipo de cambio de la peseta frente a la moneda del país $i$ en el período base y en el período $t$, respectivamente; $x i$, la ponderación que recibe cada país; $P_{0}$ y $P_{\rho}$ los índices de precios españoles en el período base y en el período $t$, respectivamente, y $P_{0}^{*}$ y $P_{t}^{*}$ los índices de precios de los países de referencia en el período base y en el período $t$. 
Definido así el índice, se considera 100 como el valor teórico de equilibrio, aunque a esto no se le debe atribuir un contenido esencialista sino más bien pragmático; en consecuencia, cuando el indicador se encuentra por encima de esa cifra, el tipo de cambio está sobrevalorado y una elevación del índice equivale siempre a pérdida de competitividad. En este ejercicio se hace recaer sobre el tipo de cambio la responsabilidad de ajustar los desequilibrios que se puedan producir en los precios relativos del país en cuestión y sus principales interlocutores comerciales. Si el tipo de cambio es lo suficientemente flexible el índice se situará en torno al 100; en caso contrario puede superarlo, si no alcanza a compensar un diferencial de precios en contra del país, o quedar por debajo, de exceder su depreciación al diferencial de precios.

En esta medición resultan cruciales el momento para el que se define el equilibrio, los países tomados como referencias y los índices de precios considerados. En nuestro caso, el valor 100 se asigna al segundo semestre del año 1959, porque el tipo de cambio vigente tras el Plan de Estabilización corrigió el desequilibrio anterior y mostró cierta capacidad para sostener establemente la balanza de pagos española algún tiempo. En estas condiciones cualquier alternativa parece más arbitraria que el tipo establecido tras el Plan, coincidente además con el que regía por entonces en el mercado libre.

Los países seleccionados son los principales socios comerciales de España: Estados Unidos, Gran Bretaña, Francia y la República Federal de Alemania, que en el decenio de los cincuenta venían a suponer el $50 \%$ de las exportaciones e importaciones españolas ${ }^{39}$. Para equilibrar los considerables cambios producidos en la composición geográfica del comercio exterior de España en la época, se toman ponderaciones actualizadas con los datos de 1950, 1952, 1954 y 1956. En cuanto a los precios, se han adoptado los precios al por mayor, por ser los que tienen más significación para el comercio internacional y, en consecuencia, para la medición de la competitividad ${ }^{40}$.

Los resultados no dejan lugar a dudas (Cuadro 4 y Gráfico 3). Desde la perspectiva de la competitividad en precios, y considerando la situación de 1959 tras el Plan de Estabilización como de equilibrio, la peseta se mantuvo sobrevalorada permanentemente a lo largo de los años cincuenta. Esto fue

39 Como se indicó anteriormente, los prolijos cálculos intermedios no pueden ser presentados aquí, por un problema de espacio, pero se encuentran a disposición de los investigadores interesados.

41) Sobre los distintos índices de competitividad en precios y costes, Marsh y Tokarick (1994), y para España en años más recientes, L'Hotellerie (1985). 


\section{CUADRO 4}

Tipo de cambio efectivo real

\begin{tabular}{cccccc}
\hline & $\begin{array}{c}\text { TCEN } \\
\text { (balanza } \\
\text { comercial) }\end{array}$ & $\begin{array}{c}\text { IPR } \\
\text { (por mayor) }\end{array}$ & $\begin{array}{c}\text { TCER } \\
(B C)\end{array}$ & $\begin{array}{c}\text { TCEN } \\
\text { Tánger }\end{array}$ & $\begin{array}{c}\text { TCER } \\
(T)\end{array}$ \\
\hline 1948 & 437,02 & 53,21 & 232,54 & 140,66 & 74,85 \\
1949 & 388,84 & 53,51 & 208,07 & 144,50 & 77,32 \\
1950 & 286,95 & 60,19 & 172,70 & 106,93 & 64,36 \\
1951 & 201,01 & 62,55 & 125,74 & 109,54 & 68,52 \\
1952 & 184,48 & 65,97 & 121,69 & 114,61 & 75,60 \\
1953 & 185,02 & 73,99 & 136,90 & 128,51 & 95,09 \\
1954 & 176,47 & 74,70 & 131,82 & 129,46 & 96,71 \\
1955 & 169,21 & 75,43 & 127,63 & 128,92 & 97,25 \\
1956 & 174,99 & 79,18 & 138,56 & 126,68 & 100,31 \\
1957 & 144,79 & 90,14 & 130,51 & 106,81 & 96,27 \\
1958 & 135,30 & 98,93 & 133,86 & 106,62 & 105,48 \\
1959 (I) & 129,80 & 100,00 & 129,80 & 100,85 & 100,85 \\
1959 (II) & 100,00 & 100,00 & 100,00 & 100,00 & 100,00 \\
\hline
\end{tabular}

FUENTES: Precios: Mitchell (1992 y 1993); Ponderaciones: Estadísticas de Comercio Exterior; Tipos de cambio: Cuadros 1 y 3, FMI (1980) y Mitchell (1988).

resultado, esencialmente, de un exceso de apreciación en el origen, consecuencia, a su vez, de haber mantenido durante los cuarenta el cambio en 10,95 pesetas por dólar, a pesar de la inflación acumulada en contra. Las devaluaciones de finales de los cuarenta y comienzos de los cincuenta mejoraron sustancialmente la competitividad, aunque no fueron lo suficientemente intensas como para situar el cambio en un punto de equilibrio y mantuvieron a la peseta apreciada en exceso. Durante los cincuenta el cambio real de la peseta se estabilizó considerablemente, aunque en los niveles muy apreciados que se acaban de indicar. De ahí las continuas dificultades de la balanza de pagos, sólo insuficientemente paliadas en el denominado bienio preestabilizador, y la necesidad de proceder a una corrección más contundente en 1959, a la postre decisiva. La escasa percepción de las relaciones entre tipo de cambio e inflación en los dos decenios a que nos referimos, algo pudo deber a la «incomunicación de la autoridad monetaria interna (Banco de España) con los movimientos exteriores de la peseta, que pasan a manos del IEME», denunciada por Sardá ${ }^{41}$.

${ }^{41}$ J. Sardá (1987), p. 316. 


\section{GRÁFICO 3}

Tipos de cambio efectivo real de la peseta

(promedio de la balanza comercial y Tánger)

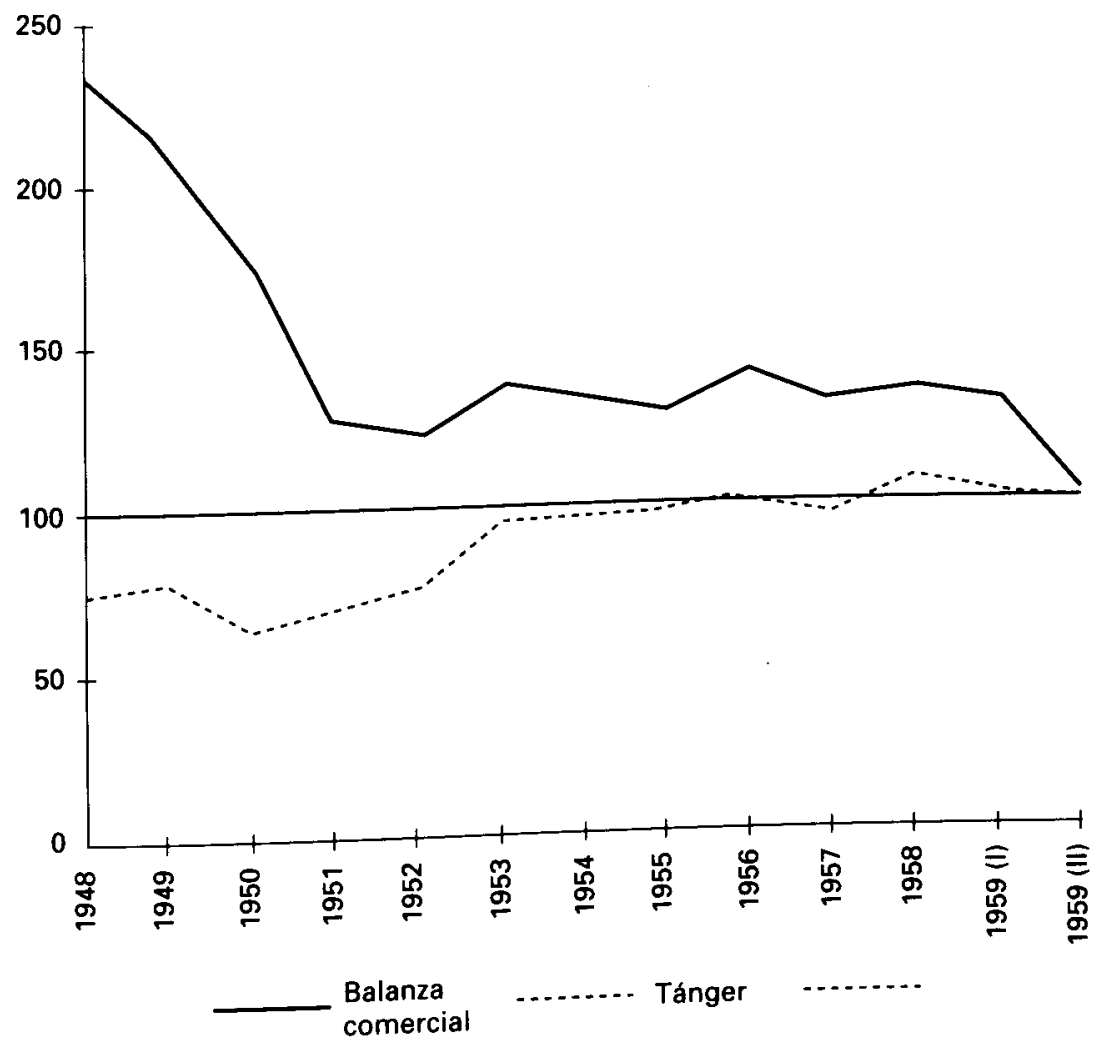

Si, por el contrario, se toma como tipo nominal para realizar los cálculos el vigente en Tánger, los resultados son muy distintos. Hasta 1953 la peseta de Tánger se encontraba excesivamente depreciada, en relación al equilibrio definido tras el Plan de Estabilización y habida cuenta de la evolución de los precios relativos. Seguramente la incertidumbre respecto a las posibilidades de la economía española, y aun del propio régimen, en aquellos años le hacían pagar a la moneda una prima de riesgo considerable. A partir de 1953 el mayor realismo en la cotización de la peseta oficial, y acaso también las intervenciones del IEME en Tánger, colocaron a la peseta 
del mercado negro en un tipo de cambio real muy cercano al valor 100 . Los resultados pueden sorprender por la precisión con que el mercado libre logró definir el punto de equilibrio de la peseta, pero ayudan a explicar la coincidencia de los tipos de cambio de Tánger y el Plan, así como su estabilidad posterior.

Ahora bien, esto no pasa de ser un mero ejercicio teórico, porque el tipo de Tánger tenía una importancia marginal en los intercambios con el exterior $y$, por ende, en la economía española, a cuya realidad es preciso volver, para concluir este trabajo. Y lo haremos con dos reflexiones finales. De una parte, al tomar en consideración el diferencial entre los tipos de cambio aplicados a la importación y a la exportación antes mostrado (Gráfico 2) y la realidad, ahora comprobada, de un exceso de apreciación de la peseta, cabe señalar alguna implicación interesante. Con estas premisas se puede afirmar que la política de tipo de cambio en los años considerados penalizó la exportación, mientras estimulaba las importaciones; las dificultades subsiguientes de la balanza de pagos son un resultado lógico de tal estrategia. Si se considera que la exportación era esencialmente agrícola y las importaciones más beneficiadas fueron maquinaria y materias primas industriales, podría hablarse también de una cierta orientación industrialista —acaso forzada y con más voluntarismo que aciertos- en el ingenierismo cambiario.

De otra parte, la alambicada política del ingenierismo cambiario fue incapaz de situar el tipo de cambio de la peseta en una senda de equilibrio y lo mantuvo permanentemente sobrevalorado a lo largo de los años cincuenta, con riesgo continuo de estrangulamiento externo. Aunque no se debe ignorar, como habitualmente se hace, la importante devaluación de finales de los cuarenta y comienzos del siguiente decenio, tampoco cabe desconocer que ya entonces resultó insuficiente para contrarrestar el movimiento de los precios relativos desde la guerra civil. La mayor estabilidad cambiaria de los cincuenta no agravó las cosas, pero tampoco corrigió la deficiencia de origen y el problema del equilibrio exterior se fue haciendo cada vez más perentorio, hasta desembocar en la crisis de finales del decenio. Un estado de necesidad que tuvo su aspecto positivo, pues impulsó la operación, a la postre brillante, del Plan de Estabilización de julio de 1959, que abrió a la economía española posibilidades de desarrollo bien aprovechadas en los sesenta. 


\section{BIBLIOGRAFÍA}

Arburúa, M. (1956): Cinco años al frente del Ministerio de Comercio. Discursos y declaraciones: 1951-1956, Madrid.

ASENSIO, M. J. (1995): «El proceso de apertura exterior de los cincuenta y el arancel de 1960», Tesis Doctoral, dirigida por el Dr. José M. Serrano Sanz y presentada en la Universidad de Zaragoza.

BAllestero, A. (1993): Juan Antonio Suanzes 1891-1977. La politica industrial de la posguerra, LID, León.

BANCO DE ESPAÑA, (1960): Informe sobre la Economía Española en 1959, Madrid, Banco de España.

CATALÁN, J. (1993): «Economía e industria: la ruptura de posguerra en perspectiva comparada», Revista de Economía Industrial, n. ${ }^{\circ} 4$.

(1995): La economía española y la segunda guerra mundial, Ariel, Barcelona.

Comín, F. (1996): Historia de la Hacienda pública II. España (1808-1995), Crítica, Barcelona.

Chamorro, S., y otros (1975): «Las balanzas de pagos de España del período de la autarquía», Información Comercial Española, (Junio), pp. 161-188.

DONGES, J. B. (1976): La industrialización en España, Barcelona: Oikos-tau, S.A.

EGUIDAZU, F. (1978): Intervención monetaria y control de cambios en España, 1900 1977, Ed. Información Comercial Española, Serie Comercio Exterior.

EICHENGREEN, B. (1993): Recostructing Europe's trade and payments, Manchester U. Press.

ESTAPÉ, F. (1972): Ensayos sobre economia española, Ariel, Barcelona.

FONDO MONETARIO INTERNACIONAL (1959): International monetary fund: $10 t h$ anual report on exchange restrictions, Washington, IMF.

- (1980): International Financial Statistics, Anuario, Washington, F. M. I.

FONTANA, J. (ed.): (1986): España bajo el franquismo, Crítica, Barcelona.

FUENTES QUINTANA, E. (1959): «Estabilización de precios y comercio exterior», Información Comercial Española (febrero).

- (1984): «El plan de estabilización económica de 1959, veinticinco años después», en Información Comercial Española, n. ${ }^{\circ} 612-13$.

(1995): El modelo de economia abierta y el modelo castizo en el desarrollo económico de la España de los años 90, PUZ, Zaragoza.

ELLSWORTH, P. T. (1962): Comercio internacional, Fondo de Cultura Económica, México.

García Delgado, J. L. (1987): «La industrialización y el desarrollo económica de España durante el franquismo», en NADAL, J., CARRERAS, A., y SUDRIÀ, C. (compil.) (1987).

García Delgado, J. L., y Jiménez, J. C. (1996): «La economía», en Historia de España Menéndez Pidal, Tomo XLI, La época de Franco (1939-1975), Espasa Calpe, Madrid.

GONZÁlEZ, M. J. (1979): La economia política del Franquismo (1940-1970), Madrid, Tecnos.

INFORMACION COMERCIAL ESPAÑOLA (1959): «Balanza de pagos de España (1953-58)», (Julio), pp. 17-32. 
L'Hotellerie, P. (1985): «Los índices de competitividad. Comentarios sobre su aplicación al caso de España», Boletín Económico, pp. 25-41, Madrid: Banco de España.

MARSH, I. W., y TOKARICK, S. P. (1994): «Competitiveness indicators: A theoretical and empirical assessment», Working Papers, 29 (marzo) International Monetary Fund, Washington.

MARTIN ACEÑA, P. (1988): Una estimación de los principales agregados monetarios en España 1940-1962, B. de España, Madrid.

- (1989): «Sistema financiero», Carreras, A. (Coor.), Estadísticas Históricas de España. Siglos XIX y XX, Banco Exterior, Madrid.

MARTÍN ACEÑA, P., y COMfN, F. (1991): INI. 50 años de industrialización en España, Espasa Calpe, Madrid.

MARTINEZ EsTÉVEZ, A. (1987): Manual de Economía aplicada. Modelos interpretativos de la economía española, Ariel, Barcelona.

MilW/ARD, A. S. (1984): The Recostruction of Western Europe 1945-51, Cambridge U. P.

-(1992): The European Rescue of the Nation-State, Routledge.

MINISTERIO DE HACIENDA (D.G.A): Estadísticas de Comercio Exterior de España, Varios años, Madrid, Dirección General de Aduanas.

MitCHELl, R. B. (1988): British Historical Statistics, Cambridge, Cambridge University Press.

(1992): International bistorical statistics. Europe, 1750-1988, New York, M. Stockton Press.

(1993): International historical statistics. The Americas, 1750-1988, Nueva York, M. Stockton Press.

NADAL, J.; CARRERAS, A., y SUdRIÀ, C. (comp.) (1987): La economía española en el siglo XX. Una perspectiva histórica, Ariel, Barcelona.

NavARro RuBio, M. (1976): «La batalla de la Estabilización», en Anales de la Real Academia de Ciencias Morales y Politicas, ${ }^{\circ}{ }^{\circ} 53$.

ORTÍNEZ, M. (1993): Una vida entre burguesos, Ed. 62, Barcelona.

PERPIÑÁ, R. (1960): «Determinantes de la estructura del comercio exterior», en Boletin de Estudios Económicos, mayo.

REAL ACADEMIA DE CIENCIAS MORALES Y POLÍTICAS (1995): Problemas económicos españoles en la década de los 90, Galaxia Gutenberg, Barcelona.

Ros HonBRAVELLA, y otros (1978): Capitalismo español: de la autarquía a la estabilización (1939-1959), Cuadernos para el Diálogo, Madrid.

SARDÁ, J. (1987): Escritos (1948-1980), B. de España, Madrid.

SERRANO SANZ, J. M. (1989): «El sector exterior de la economía española (1939. 1959)». Documento de Trabajo, 2/89 Departamento de Estructura Económica, Universidad de Zaragoza.

(1992): «La apertura exterior de la economía española en perspectiva (19011980)», en Economía española, cultura y sociedad. Homenaje a Juan Velarde, pp. 433-451, Madrid, Eudema.

- (1997): «Sector exterior y desarrollo en la economía española contemporánea», Papeles de Economía Española, n. ${ }^{\circ} 73$.

TAMAMES, R. (1975): La República. La Era de Franco, Historia de España. Alfaguara VII. Alianza Universidad. Madrid. 
TEW, B. (1965): Monetary international co-operation 1945-65, Hutchison, Londres. TORRES, M. DE (1956): Juicio de la actual política económica española, Aguilar, Madrid.

VELARDE, J. (1991): «El intento de estabilización económica española en 1947-48», Resumen de la conferencia pronunciada por el Prof. Velarde, Universidad de Barcelona: Departamento de Política Económica. Facultad de Ciencias Económicas (mimeo).

- (1995): «Evolución del comercio exterior español: del nacionalismo económico a la Unión Europea», en Real Academia de Ciencias Morales y Políticas (1995).

VelasCO, C. (1984): «El ingenierismo como directriz de la política económica durante la Autarquía (1936-1951)», en Información Comercial Española n. ${ }^{\circ} 606$.

VIÑAS, A. (1981): Los pactos secretos de Franco con Estados Unidos, Barcelona, Grijalbo.

VIÑAS, A., y otros (1979): Política comercial exterior en España (1931-1975), Madrid, Banco Exterior de España.

WEE, H. VAN DER (1986): Prosperidad y crisis. Reconstrucción, crecimiento y cambio. 1945-1980, Crítica, Barcelona. 